\title{
TRANFORMASI GAYA TARI PISO SURIT DI KABUPATEN LANGKAT
}

\author{
IRWANSYAH \\ Prodi Pendidikan Tari
}

\begin{abstract}
Abstrac
This study aimed to describe the transformation of dance styles Piso Surit located in Langkat District of done. In this discussion the use of theories related research topics such as the theory of transformation and the theory of style. The method used qualitative methods, population research traditional leaders, cultural figures and artist. File collection techniques in clude field observation, interviews, documentation, and literature study. Based on this study, it can be seen that dance Piso Surit in Langkat undergo transformation style, a style of dance that looks more open and energetic, it isinfluenced by several factors, namely:revolution, social change takes place rapidly result in changes to the dance Piso Surit, in addition to other factor such as the revolution of the internal and exsternal factors. Interna : the lack of attention from the public Karo so that the culture gradually changed mainly in art dance Piso Surit. External:Malay society is a tribal dominated area Langkat causing people Karo absorb the malay culture, one of which happens to dance Piso Surit community Karo who was in Langkat.
\end{abstract}

Keyword: Revolution, Karo tribe Society, Society Malays 


\section{PENDAHULUAN}

Karo merupakan etnis yang berada di Sumatera Utara dan mendiami beberapa wilayah sebagai tempat bermukim. Wilayah permukiman suku Karo jauh lebih luas dari pada Kabupaten Karo. Adapun wilayah yang dijadikan sebagai permukiman oleh suku Karo dari dahulu hingga sampai saat ini yaitu: Kabupaten Karo, Kabupaten Dairi, Kabupaten Aceh Tenggara, Kabupaten Deli Serdang, Kota Medan, Kota Binjai dan Kabupaten Langkat.

Tanah Langkat merupakan salah satu daerah yang dihuni oleh masyarakat Karo yang berasal dari dataran tinggi tanah Karo, yang berpindah kewilayah Langkat. Suku Melayu merupakan masyarakat asli wilayah Langkat, dengan adat istiadat dan budayanya, maka wilayah Langkat dipenuhi oleh suku Melayu yang dikenal sebagai suku Melayu Langkat. Masyarakat suku Karo yang pada awalnya mendiami wilayah inipun akhirnya sebagian memeluk agama Islam, dan ikut menyerap budaya Melayu dan ikut menjadi bahagian dari etnik Melayu, yang lebih dikenal sebagai suku Melayu Karo Langkat atau yang lebih dikenal dengan istilah Mekarlang.

Kebudayaan yang masih dipertahankan oleh masyarakat Karo antara lain perkawinan, pesta adat, kematian dan lain sebagainya. Masing-masing bentuk Upacara tersebut dilakukan dengan cara-cara tertentu yang menjadi ciri khas dari masyarakat Karo. Ciri khas tersebut disatu pihak ada yang masih dipertahankan oleh masyarakat Karo dan tidak mengalami perubahan sebagai kebudayaan yang menjadi bagian dari masyarakat Karo.

Dalam skripsi Shelvi Heryanti (2014) piso surit adalah salah satu lagu, syair, serta tarian suku Karo yang menggambarkan seorang gadis yang sedang menantikan kedatangan kekasihnya. Penantian tersebut sangatlah lama dan menyedihkan juga dapat digambarkan seperti burung piso surit yang sedang memanggilmanggil. Piso dalam bahasa Karo berarti pisau dan banyak orang mengira bahwa piso surit merupakan nama sejenis pisau khas orang Karo. 
Sebenarnya pisau surit adalah kicau burung yang suka bernyanyi. Kicau burung ini bila didengar secara seksama seperti sedang memanggilmanggil dan kedengarannya sangat menyedihkan. Burung piso surit biasanya berkicau disore hari. Jenis burung tersebut dalam bahasa Karo disebut "pincala" bunyinya nyaring dan berulang-ulang dengan bunyi seperti "piso serit".

Djaga Depari menciptakan lagu piso surit sekitar tahun 1960-an. Setelah terciptanya lagu piso surit dan sering diperdengarkan pada setiap acara-acara adat, lalu seiring berjalannya waktu maka masyarakat Karo mencoba untuk menciptakan gerak-gerak yang tidak terlepas dari gerak dasar tari Karo menjadi sebuah tarian yang sekarang ini dikenal dengan tari piso surit. Baik tari piso surit maupun tari-tari Karo yang lain semuanya berasal dari gerak dasar tari Lima Serangkai, baru kemudian dipecahkan lagi menjadi gerak-gerak yang baru untuk dijadikan sebuah tarian.

Tari Piso Surit dikenal masyarakat Langkat karena adanya orang Karo dari Kabupaten Karo yang tinggal, bermukim dan menetap di daerah Langkat. Tetapi, tidak diketahui secara pasti kapan tari piso surit ini hadir dan popular didaerah Langkat. Tetapi, tidak diketahui secara pasti kapan tari Piso Surit ini hadir dan popular disana.

Perbedaan daerah ternyata dapat menyebabkan gaya tari ini menjadi berbeda pula. Gaya yang terlihat pada tari piso surit yang ada di Kabupaten Langkat merupakan gaya yang biasanya kita lihat apabila penari Melayu menarikan tarian Melayu, namun sturuktur dan motif tarian yang ditarikan tetap tari piso surit.

Oleh karena itu penulis tertarik untuk menjadikan tari piso surit sebagai topik dalam kajian penelitiannya dengan judul “Transformasi Gaya Tari Piso Surit Di Kabupaten Langkat".

Tujuan yang ingin dicapai adalah sebagai berikut:

1. Mendeskripsikan transformasi gaya tari piso surit di Kabupaten Langkat.

2. Mendeskripsikan faktorfaktor apa saja yang 
memperngaruhi

perubahan gaya tari piso

surit di Kabupaten

Langkat

\section{Landasan Teori}

Untuk

membahas

Transformasi Gaya Tari Piso Surit di

Kabupaten Langkat penulis menggunakan teori Transformasi dan teori gaya

\section{Lokasi dan Waktu Penelitian}

Penelitian dilakukan di Desa

Perhiasan Kecamatan Selesai

Kabupaten Langkat. Waktu

penelitian dilakukan pada maret sampai mei 2016.

\section{Populasi dan Sampel}

\section{Populasi}

populasi dalam penelitian ini adalah beberapa tokoh-tokoh adat, tokoh-tokoh budaya masyarakat dan seniman serta penari tari piso surit.

\section{Sampel}

sampel dalam penelitian ini adalah 2 orang seniman dan 4 orang penari

\section{Teknik Pengumpulan Data}

Teknik pengumpulan data yang dilakukan adalah sebagai berikut:

1. Observasi

2. Wawancara

3. Dokumentasi

4. Studi Kepustakaan

\section{Teknik Analisis Data}

Dalam penelitian ini data yang digunakan adalah analisis deskriptif kualitatif dimana penelitian ini sesuai dengan fakta sosial dan memberi gambaran, keterangan serta uraian.

\section{ISI}

\section{Asal Usul Orang Karo}

Asal-usul orang Karo selalu diidentikkan dengan Kerajaan Haru. Didalam legenda suku Karo, bahwa sebuah kerajaan besar bernama Haru pernah berdiri di Sumatera. Pada mulanya bangsa ini bernama suku bangsa Haru, kemudian disebut Haru, dan akhirnya dinamai suku bangsa Karo, khusus untuk nama yang menghuni wilayah suku bangsa Karo. Menurut cerita mayarakat Karo Langkat, Setelah hancur 
Kerajaan Haru Wampu, Kerajaan Lingga Timur, Kerajaan Haru Deli Tua pada abad 16 akibat agresi bala tentara Kesultanan Aceh ke wilayah bangsa Haru maka sejak itulah pecahnya bangsa Haru menjadi beberapa suku bangsa. Yaitu Suku Bangsa Karo, Simalungun, Pakpak, Alas, Gayo, Singkel dan Keluat.

Jika ditelusuri dari sejarah Kerajaan Haru, sebenarnya migrasi orang Karo dari pantai atau pesisir menuju pedalaman atau pegunungan membentuk arus bolak-balik. Sarjani Tarigan, 2009 dalam bukunya "Lentera orang Karo dalam Berbudaya" mengatakan bahwa setelah penaklukan Kerajaan Haru di Deli Tua, orang Karo lari ke pedalaman dataran tinggi Karo. Secara alamiah karena dimakan waktu, pertumbuhan penduduk, arus pendatang berikutnya menjadikan sebuah desa. Untuk memenuhi kebutuhan ekonomi (perlanja sira), perdagangan hewan dan hasil bumi lainnya dan juga dalam rangka perluasan kekuasaan atau perladangan karena mereka harus mencari lahan baru dan menanam lada di daerah pesisir, orang Karo yang sudah didataran tinggi kembali ke pesisir seperti di Langkat.

\section{Tari Piso Surit di Kabupaten Langkat}

Tari piso surit adalah salah satu tarian kreasi masyarakat suku Karo di Sumatera Utara. Tarian ini termasuk tarian selamat datang yang biasanya ditampilkan secara berkelompok oleh para penari pria dan wanita. Tari piso surit ini cukup terkenal di Sumatera Utara, terutama di daerah Karo sebagai daerah asalnya. Tarian ini sering ditampilkan di berbagai acara seperti penyambutan tamu agung, acara adat, dan acara budaya, tidak jauh bedanya dengan masyarakat Karo di Langkat, tari piso surit juga ditarikan sebagai penyambutan tamu agung.

Kebudayaan yang ada di Langkat yang berkembang sangat beraneka ragam baik didaerah Langkat Hulu maupun didaerah Langkat Hilir, yang asli maupun yang bercampur dengan budaya pendatang, semuanya kekayaan daerah yang tak ternilai harganya. Salah satu budaya yang berkembang di daerah Langkat adalah seni tari tradisional. Seperti halnya tari piso 
surit yang sudah sangat dikenal pada tingkat Nasional. Seperti yang telah dijelaskan sebelumnya bahwa tari piso surit adalah sebuah tari kreasi yang mentradisi pada masyarakat Karo, tetapi masyarakat Karo sudah menganggap tarian ini masuk dalam salah satu tari tradisi Kebudayaan Karo.

\section{Ragam Gerak}

Ragam-ragam gerak yang terdapat pada tari piso surit tidak semuanya memiliki sebutan atau istilah yang secara detail dapat dijabarkan dalam bahasa Karo. Maka dari itu motif-motif ragam gerak tari piso surit ini hanya dapat dijabarkan dalam bahasa Indonesia. Tari piso surit memiliki banyak variasi dalam susunan urutan dan motif gerak antara tari piso surit yang lainnya. Variasi yang dibuat pada gerak tari piso surit itu tidak bisa disalahkan, hal ini bisa saja terjadi dari pola maupun struktur garapan yang ditata sedemikian rupa, berdasarkan ragam kinestetik yang sudah ada hingga dikreasikan menjadi versi baru tari piso surit pada lokasi yang berbeda.

Ada 5 (lima) motif gerak dasar pada tari piso surit yang penulis teliti, adapun lima motif tersebut ialah:

\begin{tabular}{|c|c|c|}
\hline No & $\begin{array}{l}\text { Motif } \\
\text { Gerak }\end{array}$ & Deskriptif \\
\hline 1 & $\begin{array}{l}\text { Tengah } \\
\text { Rukur }\end{array}$ & $\begin{array}{l}\text { Tangan } \\
\text { kiri keatas } \\
\text { gerak } \\
\text { tangan } \\
\text { kanan } \\
\text { kebawah. }\end{array}$ \\
\hline 2 & $\begin{array}{l}\text { Sisampat- } \\
\text { sampaten. }\end{array}$ & $\begin{array}{l}\text { Tangan } \\
\text { kanan } \\
\text { keatas, } \\
\text { gerak } \\
\text { tangan kiri } \\
\text { kebawah. }\end{array}$ \\
\hline 3 & $\begin{array}{l}\text { Perarihen } \\
\text { enteguh }\end{array}$ & $\begin{array}{l}\text { Tangan } \\
\text { memutar } \\
\text { dan } \\
\text { mengepal. }\end{array}$ \\
\hline 4 & $\begin{array}{l}\text { Ise pai reh } \\
\text { adi ertutur } \\
\text { ialo-alo } \\
\text { alu mehuli }\end{array}$ & $\begin{array}{l}\text { Tangan } \\
\text { kiri dan } \\
\text { tangan } \\
\text { kanan } \\
\text { ketengah } \\
\text { dan posisi } \\
\text { badan } \\
\text { berdiri. }\end{array}$ \\
\hline 5 & $\begin{array}{l}\text { Beban } \\
\text { simberat } \\
\text { ras } \\
\text { menahang } \\
\text { ras ibaba }\end{array}$ & $\begin{array}{l}\text { Tangan } \\
\text { kanan dan } \\
\text { kiri } \\
\text { sampai } \\
\text { bahu. }\end{array}$ \\
\hline
\end{tabular}


Ragam Gerak tari piso surit di Kabupaten Langkat

\begin{tabular}{|c|c|c|}
\hline No & $\begin{array}{l}\text { Ragam } \\
\text { Gerak }\end{array}$ & Uraian \\
\hline 1 & $\begin{array}{l}\text { Awal } \\
\text { Masuk. }\end{array}$ & $\begin{array}{l}\text { Kedua penari } \\
\text { berjalan } \\
\text { ditempat } \\
\text { dengan posisi } \\
\text { kedua tangan } \\
\text { mengembang } \\
\text { di samping } \\
\text { badan. }\end{array}$ \\
\hline 2 & $\begin{array}{l}\text { Tengah } \\
\text { Rukur } \\
\text { putar } \\
\text { kanan. }\end{array}$ & $\begin{array}{l}\text { Hitungan } 1 x 8 \\
\text { Kedua penari } \\
\text { melakukan } \\
\text { gerakan putar } \\
\text { kanan dengan } \\
\text { posisi tangan } \\
\text { kiri diatas dan } \\
\text { tangan kanan } \\
\text { dibawah. }\end{array}$ \\
\hline 3 & $\begin{array}{l}\text { Tengah } \\
\text { Rukur } \\
\text { putar kiri. }\end{array}$ & $\begin{array}{l}\text { Hitungan } 1 x 8 \\
\text { kedua penari } \\
\text { melakukan } \\
\text { gerakan putar } \\
\text { kiri dengan } \\
\text { posisi tangan } \\
\text { kanan diatas } \\
\text { tangan kiri } \\
\text { dibawah. }\end{array}$ \\
\hline 4 & $\begin{array}{l}\text { Dilanjutkan } \\
\text { gerakan } \\
\text { Perarihen } \\
\text { enteguh }\end{array}$ & $\begin{array}{l}\text { Gerakan } \\
\text { tangan } \\
\text { mengayun dan } \\
\text { memutar } \\
\text { langkah kaki } \\
\text { ditempat. }\end{array}$ \\
\hline 5 & $\begin{array}{l}\text { Berjalan } \\
\text { tukar posisi }\end{array}$ & $\begin{array}{l}\text { Hitungan } 1 x 8 \\
\text { kedua penari }\end{array}$ \\
\hline
\end{tabular}

\begin{tabular}{|c|c|c|}
\hline & & $\begin{array}{l}\text { berjalan } \\
\text { menempati } \\
\text { posisi } \\
\text { pasangan } \\
\text { dengan } \\
\text { gerakan tangan } \\
\text { kanan diatas } \\
\text { dan tangan kiri } \\
\text { dibawah } \\
\text { sejajar dengan } \\
\text { pasangan }\end{array}$ \\
\hline 6 & $\begin{array}{l}\text { Berjalan } \\
\text { kembali } \\
\text { ketempat }\end{array}$ & $\begin{array}{l}\text { Hitungan 1x8 } \\
\text { kedua penari } \\
\text { berjalan } \\
\text { kembali ke } \\
\text { posisi masing- } \\
\text { masing dengan } \\
\text { gerakkan } \\
\text { tangan kanan } \\
\text { diatas dan } \\
\text { tangan kiri } \\
\text { dibawah } \\
\text { sejajar dengan } \\
\text { pasangan }\end{array}$ \\
\hline 7 & $\begin{array}{l}\text { Berjalan } \\
\text { mendekat } \\
\text { sambil } \\
\text { sambil } \\
\text { melakukan } \\
\text { gerakan } \\
\text { tangan isa } \\
\text { pai reh adi } \\
\text { ertutur } \\
\text { ialo-alo alu } \\
\text { mehuli }\end{array}$ & $\begin{array}{l}\text { Dalam } \\
\text { hitungan } 1 x 8 \\
\text { kedua penari } \\
\text { perlahan-lahan } \\
\text { mendekat } \\
\text { dengan posisi } \\
\text { kedua tangan } \\
\text { kedepan }\end{array}$ \\
\hline 8 & $\begin{array}{l}\text { Jalan } \\
\text { beriringan } \\
\text { kebelakang }\end{array}$ & $\begin{array}{l}\text { Tangan kiri } \\
\text { penari wanita } \\
\text { berada sejajar } \\
\text { bahu dan } \\
\text { tangan kanan } \\
\text { dibawah, } \\
\text { sedangkan } \\
\text { tangan kanan } \\
\text { penari pria } \\
\text { berada sejajar } \\
\text { bahu dan }\end{array}$ \\
\hline
\end{tabular}




\begin{tabular}{|c|c|c|}
\hline & & $\begin{array}{l}\text { tangan kiri } \\
\text { dibawah } \\
\text { hitungan } 1 \times 8\end{array}$ \\
\hline 9 & $\begin{array}{l}\text { Jalan } \\
\text { beriringan } \\
\text { maju } \\
\text { kedepan }\end{array}$ & $\begin{array}{l}\text { Tangan kanan } \\
\text { penari wanita } \\
\text { berada sejajar } \\
\text { bahu dan } \\
\text { tangan kiri } \\
\text { dibawah, } \\
\text { sedangkan } \\
\text { tangan kiri } \\
\text { penari pria } \\
\text { berada sejajar } \\
\text { bahu dan } \\
\text { tangan kanan } \\
\text { dibawah }\end{array}$ \\
\hline 10 & $\begin{array}{l}\text { Ragam } \\
\text { jongkok, } \\
\text { saling } \\
\text { condong }\end{array}$ & $\begin{array}{l}\text { Awalnya } \\
\text { kedua penari } \\
\text { berdiri dengan } \\
\text { gerakan tangan } \\
\text { kiri dan kanan } \\
\text { ketengah } \\
\text { posisi badan, } \\
\text { kemudian } \\
\text { perlahan-lahan } \\
\text { turun kebawah } \\
\text { dengan posisi } \\
\text { tangan kanan } \\
\text { diatas dan } \\
\text { tangan kiri } \\
\text { dibawah, dan } \\
\text { melakukan } \\
\text { gerakkan } \\
\text { jongkok penari } \\
\text { pria condong } \\
\text { kearah penari } \\
\text { wanita }\end{array}$ \\
\hline 11 & $\begin{array}{l}\text { Ragam } \\
\text { jongkok } \\
\text { saling } \\
\text { condong }\end{array}$ & $\begin{array}{l}\text { Awalnya } \\
\text { kedua penari } \\
\text { berdiri dengan } \\
\text { gerakan tangan } \\
\text { kiri dan kanan } \\
\text { ketengah } \\
\text { posisi badan, } \\
\text { kemudian } \\
\text { perlahan-lahan }\end{array}$ \\
\hline
\end{tabular}

\begin{tabular}{|c|c|c|}
\hline & & $\begin{array}{l}\text { turun kebawah } \\
\text { dengan posisi } \\
\text { tangan kanan } \\
\text { diatas dan } \\
\text { tangan kiri } \\
\text { dibawah, dan } \\
\text { melakukan } \\
\text { gerakkan } \\
\text { jongkok penari } \\
\text { wanita } \\
\text { condong } \\
\text { kearah penari } \\
\text { pria }\end{array}$ \\
\hline 12 & $\begin{array}{l}\text { Ragam } \\
\text { menghadap } \\
\text { kedepan }\end{array}$ & $\begin{array}{l}\text { Kedua penari } \\
\text { menghadap } \\
\text { posisi depan } \\
\text { dengan posisi } \\
\text { tangan sejajar } \\
\text { bahu yang } \\
\text { melambangkan } \\
\text { beban siberat } \\
\text { ras si menahan } \\
\text { ras } i \\
\text { bada,yang } \\
\text { artinya berani } \\
\text { berbuat harus } \\
\text { berani } \\
\text { bertanggung } \\
\text { jawab }\end{array}$ \\
\hline 13 & $\begin{array}{l}\text { Salam } \\
\text { penutup }\end{array}$ & $\begin{array}{l}\text { Badan sedikit } \\
\text { membungkuk } \\
\text { kemudian } \\
\text { kedua tangan } \\
\text { bertepuk tetapi } \\
\text { tidak } \\
\text { menimbulkan } \\
\text { suara keras, } \\
\text { kemudian } \\
\text { kedua tangan } \\
\text { lurus kebawah. }\end{array}$ \\
\hline
\end{tabular}

\section{Transformasi}

Tari piso surit berfungsi dalam kegiatan kemasyarakatan, sebagai 
pertunjukkan hiburan dan tontonan pada acara perkawinan, sunatan, dan pesta rakyat. Tarian tidak akan pernah terlepas dari beberapa elemen, seperti gerak, pola lantai, tata rias, tata busana, musik pengiring, pentas, dan gaya.

Tari piso surit ini juga tidak terlepas dari unsur-unsur pelengkap atau pendukung yang mengalami transformasi dari tari Piso surit ialah gerak dan Busana. Bagian tersebut dijelaskan sebagai berikut.

1) Gerak

Gerak yang mengalami transformasi tidaklah begitu banyak, hanya saja terdapat beberapa perbedaan seperti, saat melakukan gerak, terdapat perbedaan enjut atau endek. Pardamenta sembiring mengatakan endek yang berada di kabupaten Karo lebih lembut dari endek yang berada di Kabupaten Langkat. Pengaruh ini disebabkan di Kabupaten Karo merupakan wilayah pegunungan beda dengan di Kabupaten Langkat yang jalannya di dataran rendah. Penjelesan ini bukanlah satu-satunya perbedaan dari tari piso surit.

2) Busana
Perubahan yang terjadi di Kabupaten Langkat penari wanitanya tidak mengenakkan uis di bahu, sedangkan di Kabupaten Karo mengenakan uis di bahu.

\section{Gaya}

Melayu merupakan jatidiri Kabupaten Langkat terutama didaerah Kecamatan Selesai, masuknya suku Karo kedaerah Langkat dalam upaya pengembangan wilayah, ekonomi, perdagangan, dan pekerjaan.

Mengharuskan masyarakat suku Karo membaur dengan lingkungan yang ada di Kabupaten Langkat, hal ini menyebabkan masyarakat Karo menyerap kebudayan Melayu salah satunya yang terjadi pada gaya tari piso surit masyarakat Karo yang berada diLangkat.

\section{Faktor yang mempengaruhi}

\section{transformasi gaya tari piso surit}

Faktor yang mempengaruhi terjadinya Transformasi tari Piso Surit yang terjadi di Kecamatan Selesai ini disebabkan revolusi, internal dan eksternal. 


\section{PENUTUP}

\section{Kesimpulan}

Dari semua yang telah diteliti dilapangan dan berdasarkan dengan uraian yang sudah dijelaskan mulai dari latar belakang ampai pembahasan, maka penulis dapat menyimpulkan keseluruhan dari hasil penelitian penelitian terhadap Transformasi Gaya Tari Piso Surit di Kabupaten Langkat sebagai berikut:

1. Perpindahan orang Karo ke Kabupaten Langkat membentuk suatu arus bolak-balik, yaitu orang Karo dari pantai ke gunung dan turun gunung kembali kedaerah pantai disebabkan oleh faktor ekonomin dan perluasan wilayah.

2. Tari Piso Surit adalah sebuah tari kreasi yang mentradisi, yang diciptakan oleh masyarakat Karo itu sendiri. Tari Piso Surit memiliki banyak versi namun tetap berpijak pada gerak-gerak dasar tari Karo.

3. Ada 3 hal yang perlu diperhatikan dalam tari Karo yaitu: endek, jole atau jemol, dan tan lempir. Ketiga hal ini pula yang menjadi dasar acuan penulis dalam membandingkan gaya tari Piso Surit.

4. Transformasi gaya tari Piso Surit di Kabupaten Langkat dipengaruhi oleh perbedaaan wilayah dan masyarakat sekitar. Di Kabupaten Langkat mayoritas bersuku Melayu.

5. Gaya gerak tari Piso Surit lebih terbuka, energik dan sedikit memainkan pinggul, gaya tari melayu dimana penari melakukan gerakkan denganposisi badan yang sedikit tegak dan membusungkan dada.

\section{Saran}

Berdasarkan beberapa kesimpulan yang telah diuraikan diatas, maka penulis memberikan beberapa saran yaitu:

1. Kepada seniman dan masyarakat Karo, diharapkan dapat menjaga dan meletarikan tari serta kesenian lain agar tetap terjaga kelestariannya dan budaya daerah ini tidak tergantikan oleh budaya luar.

2. Kepada seniman-seniman tari suku Karo diharapkan agar tari Piso Surit agar sepakat 
membakukan gerak tari supaya tidak terlalu banyak versinya dan tetap terjaga keaslian geraknya.

3. Kepada generasi muda, pelajari dan pertahankan budaya serta kesenian asli suku Karo khususnya kebudayaannya, serta suku-suku yang ada di Indonesia agar tetaplestari dan bisa membuat kita bangga menjadi orang Indonesia yang kaya akan suku, budaya dan keseniannya.

\section{DAFTAR PUSTAKA}

Anya, Peterson. 2007. Antropology of Dance terjemahan F.X Widaryanto, Bandung: STSI Press

Arikunto. 1993. Prosedur Penelitian Suatu Pendekatan Praktek. Jakarta : Rehekka.

Aziz Alimut Hidayah, 2007. Metode Penelitian Kebidanan dan Teknik Analisis Data, Surabaya: Salemba Media

Boskoff, Alvin. 1964. Recent Theoris of Social Change" Warner J. Cahman dan Alvin Boskoff, Sociology and History: Theory and reseach. London: The Free Press of Glencoe.

E.B. Tylor 1871. Primitive Culture. New York: Brentano;s.

Heryanti, Shelvi 2014. Tari Piso Surit Masyarakat Karo Kajian Komparatif Terhadap Gaya dan Nilai Estetika di Kabupaten Karo dan Kabupaten Langkat. Skripsi. Medan: Universitas Negeri Medan

I Made Wirartha, 2005. Pedoman Penulisan Usulan Penelitian, Skripsi dan Tesis: Andi Offset.

Indrianto. 2001. Tari Klasik Gaya Surakarta dan Yogyakarta. Jurnal Pengetahuan dan Pemikiran Seni. Semarang: Universitas Negeri Semarang. 
Lestari, Eka. 2015. Bentuk Penyajian Tari Mbuah Page Pada UpacaraKerja Tahunan Masyarakat Karo Di Desa Dokan Kecamatan Merek Kabupaten Karo. Skripsi. Medan: Universitas Negeri Medan.

Koentjaraningrat.1970.

Kebudayaan,Metalitas dan Pembangunan. Jakarta: Gramedia

Koentjaraningrat, 1987. Metodemetode Penelitian Masyarakat. Jakarta: Gramedia

Nurhasanah. 2011. Bentuk Penyajian dan Nilai Estetika Tari Piso Surit Pada Masyarakat Karo. Skripsi. Medan: Universitas Negeri Medan.
Novita Sari Dea. 2015. Trancformasi Tari Saman Kajian Dalam Konteks Pariwisata Di Kota Banda Aceh. Skripsi. Medan: Universitas Negeri Medan

Sachari, Agus dan Sunarya, Yan Yan, 1998. Reformasi Budaya Kita. Bandung

Sugiono. 2008. Metode Penelitian Pendidikan. Bandung: Alfabeta.

Surakhmad, Winarno. 1982. Pengantar Penelitian Ilmiah Dasar. Bandung: Angkasa.

$\underline{\text { Http://id.wikipedia.org/wiki/Kabupat }}$ enLangkat

Http://id.wikipedia.org/wiki/Kabupat enKaro

Http.//id.wikipedia.org/wiki/piso_sur it 